\title{
ASPECTOS TÉCNICOS E ECONÔMICOS DA ENGORDA DE LAGOSTAS: A EXPERIÊNCIA DO VIETNAM E PERSPECTIVA DE DESENVOLVIMENTO DA ATIVIDADE NO NORDESTE BRASILEIRO
}

Marco Antonio Igarashi ${ }^{1}$

IGARASHI, M. A. Aspectos técnicos e econômicos da engorda de lagostas: a experiência do Vietnam e perspectiva de desenvolvimento da atividade no nordeste brasileiro. Arq. Ciênc. Vet. Zool. UNIPAR, Umuarama, v. 21, n. 3, p. 115-122, jul./ set. 2018.

RESUMO: A proposta desta revisão é resumir as informações sobre os estudos da engorda de lagostas em gaiolas no Vietnam. Esta sinopse demonstra que os juvenis podem ser cultivados sob regime de confinamento e se adapta bem as condições artificiais com alimentação. Na aquicultura, na engorda de juvenis de lagostas capturadas na natureza (Palinuridae) até o tamanho comercial está emergindo no Vietnam. No Vietnam o cultivo de lagostas em gaiolas no mar começou na década de 1990. Nesse contexto tradicionalmente a Panulirus ornatus e outras espécies são alimentadas com rejeito de pesca e pescado de baixo valor. O objetivo global da engorda pode ser o alívio da pobreza, e neste respeito para os criadores de lagostas é em particular uma oportunidade atrativa para brasileiros devido à captura de pós-larvas de lagostas (com autorização dos órgãos competentes) e sua engorda envolve tecnologia simples, mínimo de capital, e é apropriado como uma atividade alternativa de renda para pescadores.

PALAVRAS-CHAVE: Densidade. Engorda. Gaiola. Lagosta espinhosa.

\section{TECHNICAL AND ECONOMIC ASPECTS OF SPINY LOBSTER GROWOUT: THE VIATNAMESE EXPERIENCE AND DEVELOPMENT PERSPECTIVE FOR THE ACTIVITY IN NORTHEASTERN BRAZIL}

\begin{abstract}
The purpose of this review is to sumarize the studies on spiny lobster cage farming in Vietnam. The review showed that spiny lobster juveniles can be held in communal culture systems, since they adapt well to the artificial feeding conditions. In aquaculture, the growout phase of wild-caught juvenile spiny lobsters (Palinuridae) to market size is an emerging sector in Vietnam. Spiny lobster farming in sea cages commenced in the 1990s in Vietnam. Traditionally, Panulirus ornatus lobster and other species are fed with bycatch and cheap fish. The main purpose of the growout phase can be the decrease in poverty, and in this respect lobster farming is a particularly attractive opportunity for Brazil, since the capture of post-hatching lobsters (with authorization of the competent organs) and their growout involves simple technology, minimal capital and is ideally suited as an alternative activity for income generation for fisherman.

KEY WORDS: Cage. Growout. Spiny lobster. Stocking density.

\section{ASPECTOS TÉCNICOS Y ECONÓMICOS DEL ENGORDE DE LANGOSTA: LA EXPERIENCIA DE VIETNAN Y PERSPECTIVA DE DESARROLLO DE LA ACTIVIDAD EN NORDESTE BRASILEÑO}

RESUMEN: La propuesta de esta revisión es resumir las informaciones sobre los estudios de engorde de langostas en jaulas en Vietnan. Esta sinopsis demuestra que los juveniles pueden cultivarse en régimen de confinamiento y se adapta bien a las condiciones artificiales de alimentación. En la acuicultura, el engorde de juveniles de langostas capturadas en la naturaleza (Palinuridae) hasta el tamaño comercial, está emergiendo en Vietnan. Allá el cultivo de langostas en jaula en el mar empezó en la década de 1990. En ese contexto tradicionalmente la Panulirus ornatus y otras espécies son alimentadas con desechos de pesca y pescado de bajo valor. El objetivo global de engorde puede ser el alivio de la pobreza, y con relación a los creadores de langostas es en particular una atractiva oportunidade para brasileños, debido a la captura poslarvas de langostas (con autorización de los órganos competentes), y su engorde involucra tecnologia simple, mínimo de capital, y es apropriado como uma actividad alternativa de renta para los pescadores.

PALABRAS CLAVE: Densidad. Engorde. Jaula. Langosta espinosa.

Introdução

O desenvolvimento da engorda de lagostas tem recebido uma atenção elevada nos anos recentes, enquanto a pesca tem se estabilizado ou declinado e, a demanda pelas lagostas continua aumentando. Smith et al. (2017) relataram que as lagostas possuem uma distribuição global desde as zonas de clima tropical a temperada, com mais de 40 espécies comercialmente capturadas. De acordo com os mesmos auto- res a respeito do aumento na captura por unidade de esforço em muitas capturas, o total desembarcado tem estabilizado em aproximadamente 80.000 toneladas.

Vários países como Austrália, Nova Zelândia, Índia, Vietnan, Cuba, Cingapura, África do Sul, Bahamas, Malásia, México, Ilhas Turcas e Caicos, Namíbia, Filipinas, EUA, Indonésia, Ilhas Virgens Britânicas e Nova Caledônia, desenvolvem pesquisas para realizar o cultivo de lagostas a partir da captura dos pueruli ou juvenis (PHILLIPS et. al., 2013). 
Muitas populações de lagostas ao redor do mundo parecem estar em declínio devido ao assentamento reduzido de suas pós-larvas ou pueruli (ECHAURI; JEFFS, 2017). Uma hipótese para este declínio é a mudança climática que está impactando a habilidade da larva de acumular fonte nutricional suficiente para suportar o estágio de puerulus que não se alimenta, o qual está envolvido na migração de longas distâncias para ambientes costeiros, onde eles se assentam e se tornam juvenis (FITZGIBBON; JEFFS; BATTAGLENE, 2014).

No Vietnã, a produção anual de lagosta cultivada por meio da engorda pode exceder 1.500 toneladas utilizando um suprimento natural de puerulus (PRIYAMBODO; JONES; SAMMUT, 2017).

No Vietnã, por exemplo, o total de captura de $P$. ornatus de oito províncias no período de 2006-2007 e 20092010 foi de aproximadamente um milhão de pueruli, aproximadamente metade da captura relatada em outros períodos (DAO, 2016). A longo prazo a sustentabilidade desta captura e, portanto, a engorda é incerta e é de preocupação. Porém, esta preocupação pode ser anulada pelo iminente estabelecimento de um laboratório de suprimento de pueruli (JONES, 2010). Nesse contexto, as lagostas tropicais (P. ornatus) e a vermelha ( $P$. argus) são as melhores candidatas para aquicultura por terem o mais curto período de desenvolvimento larval de quatro a oito meses (DENNIS; PITCHER; SKEWES, 2001) e rápido crescimento pós-larval (WILLIAMS, 2007). No entanto, no momento ainda não há produção comercial de pueruli e poucos pueruli são produzidos em laboratório.

Entretanto, já existe um considerável interesse mundial no potencial de cultivo de lagostas, devido possivelmente ao aumento da demanda do mercado e no limitado estoque natural deste crustáceo. Dessa forma, pesquisas desenvolvidas em outros países e no Brasil indicam tratar-se de uma atividade teoricamente promissora, apresentando, todavia óbices no campo prático. No Brasil a maioria dos estudos estão relacionados com a captura da lagosta. Portanto, devido à escassez de informações e a importância econômica das lagostas no Brasil, a presente sinopse procura demonstrar o potencial da engorda da lagosta.

\section{Desenvolvimento}

\section{Aspectos da engorda de lagostas}

As lagostas possuem vários atributos que sugerem ter potencial para a engorda, tal como alta demanda de mercado e comportamento gregário. Porém, a produção comercial em laboratório de sementes (pós-larvas) não é viável devido ao longo período larval de filosoma (KITTAKA, 1994). Portanto, as pós-larvas devem ser capturadas na natureza.

A Figura 1 a seguir demonstra lagosta Panulirus ornatus, a principal espécie utilizada na engorda. $\mathrm{Na}$ engorda de lagostas no Vietnã elas alimentam-se com rejeito de pesca e a espécies de lagostas são representadas por $75 \%$ de $P$. ornatus e $25 \%$ de $P$. homarus (JONE, 2015). No entanto, pós-larvas de $P$. versicolor, $P$. longipes e $P$. stimpsoni podem também ser utilizadas para a engorda (RADHAKRISHNAN, 2012).
Figura 1: A lagosta espinhosa Panulirus ornatus

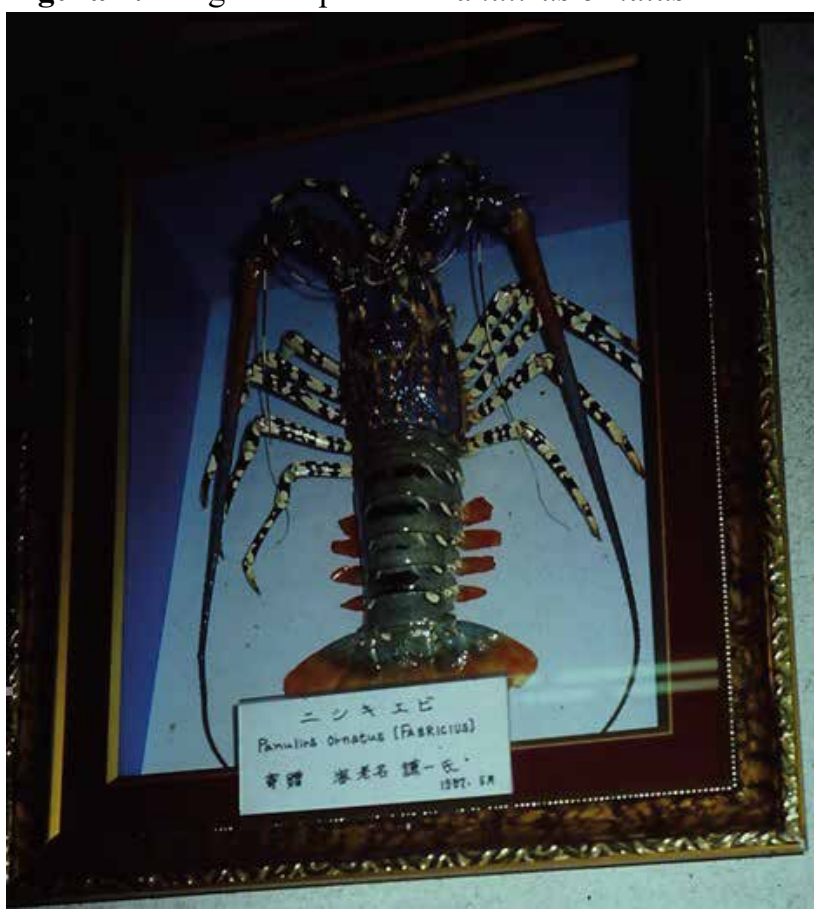

Fonte: Arquivo pessoal

A sustentabilidade das pós-larvas e juvenis de lagosta sendo capturadas para a engorda, deve ser avaliada (HUNG; TUAN, 2009) até que a produção larval de lagosta em cativeiro seja viável comercialmente.

A aquicultura baseada no suprimento natural de sementes, não é exclusivo de lagostas (JONES, 2010). Empreendimentos substanciais têm sido estabelecidos para outros crustáceos e peixes (LUCAS; SOUTHGATE, 2003).

Embora as pesquisas demonstrem que os juvenis de lagostas podem ser mantidos com êxito em sistemas convencionais de engorda, a um custo mais módico, adaptam-se bem às condições artificiais e alimentares.

\subsection{Gaiolas}

Diferentes tipos de gaiolas são usados para engorda de lagostas no Vietnã. Nesse contexto há três principais tipos de gaiolas utilizadas para engorda de lagostas, dependendo da área cultivada e da capacidade financeira dos criadores (NGUYEN, 2009). Os juvenis capturados são usados para o cultivo (PILLAI, 2013). No Vietnã, o cultivo de lagostas em gaiolas flutuantes, fixas e submersas foram praticadas em baías protegidas ou lagoas que tem um bom fluxo de maré.

A história do cultivo de lagostas no Vietnã é demonstrado no Quadro 1. 
Quadro 1: Os principais eventos na história do desenvolvimento da engorda de lagostas no Vietnan (LE ANH; JONES, 2015)

\begin{tabular}{|c|l|}
\hline Período & \multicolumn{1}{|c|}{ Principais acontecimentos } \\
\hline $1975-1985$ & Captura anual < 100 t; P. ornatus - parte moderada do suprimento, somente demanda local modesta \\
\hline $1986-1991$ & Demanda chinesa por lagostas aumentou rapidamente, especialmente para P. ornatus $>1 \mathrm{~kg}$ \\
\hline $1992-1995$ & Pescadores começaram a engordar lagostas; gaiolas fixas, produção $<100 \mathrm{t}$ \\
\hline $1996-1999$ & Pescadores começaram a coletar os pueruli natante; produção $<300 \mathrm{t}$ \\
\hline $2000-2006$ & Principalmente gaiolas flutuantes; produção de $500-2000 \mathrm{t}$; sinal de sobrecarga \\
\hline $2007-2009$ & Problemas de doenças; produção $\sim 860 \mathrm{t}(2008 / 2009) ;$ implementação do plano industrial pelo governo \\
\hline $2010-2014$ & A indústria se recuperou, a produção em 2010 para 2014 foi de aproximadamente 1.500 toneladas por ano. \\
\hline
\end{tabular}

No Vietnã, gaiolas de cultivo no mar de lagostas (principal espécie P. ornatus) foram desenvolvidas em 1992, o qual se expandindo significativamente no centro sul do Vietnã em 2000 (HUNG; TUAN, 2009). No final da década de 1990 a engorda de lagosta foi principalmente localizada em águas rasas de 100 a $500 \mathrm{~m}$ longe da praia e consistiu de gaiolas com estacas no fundo do mar (THUY; NGOC, 2004). Jones (2010) relatou que as armações para suportar as gaiolas foram feitas de material barato disponível no local, incluindo bamboo e madeira bruta cortada das florestas adjacentes, fixadas juntas com cordas de amarração. De acordo com o mesmo autor as gaiolas foram feitas de rede de pesca, as dimensões foram tipicamente $3 \mathrm{~m}^{2}$ e $2 \mathrm{~m}$ de profundidade, e o fundo da gaiola estava em contato direto com o substrato. Jone (2015) relatou que existem 35.000 a 50.000 gaiolas e juvenis de $50 \mathrm{~g}$ atingem um quilo em 20 meses com sobrevivência de 70 a $90 \%$.

A FAO (2011) relatou que a engorda em Lombok na Indonésia é realizada em gaiolas flutuantes que tem sido adaptada de gaiolas para garoupas e eles são tipicamente um pouco menores que as do Vietnã, dois a três metros de comprimento de cada lado e dois metros de profundidade. De acordo com o mesmo órgão um criador típico de lagosta na Indonésia tem cinco a dez gaiolas para engorda de $P$. homa$r u s$, enquanto no Vietnã um criador típico de lagosta tem 40 a 60 gaiolas para a produção de $P$. ornatus. A indústria do cultivo de lagostas, baseado somente em Lombok, consistiu de aproximadamente 2.000 gaiolas no mar em 2012 (PRIYAMBODO; JONES; SAMMUT, 2017).

\subsubsection{Gaiolas submersas}

A gaiola submersa (Figura 2) é usada para berçário de lagostas juvenis e para fazendas de engorda (PILLAI, 2013). A estrutura é feita de madeira com diâmetro de 15 a $16 \mathrm{~mm}$ (NGUYEN, 2009) ou a armação é feita de arame de ferro com oito a $12 \mathrm{~mm}$ de diâmetro (NGUYEN, 2012). A forma do fundo é retangular ou quadrado, com uma área normalmente entre um e $16 \mathrm{~m}^{2}$ (LE ANH; JONES, 2015) e a altura é de um a um metro e meio (TUAN; MAO, 2004).

A FAO (2011) relatou que as gaiolas berçários flutuantes podem ter o tamanho de $3 \times 3 \times 2$ metros de profundidade, consistindo de rede fina, suspenso da armação de bamboo flutuante e as gaiolas são guarnecidas com macroalgas ( $\mathrm{Gra}$ cillaria sp.), o qual provê abrigos para pequenas lagostas. De acordo com o mesmo órgão elas são também alimentadas com peixes frescos picados e engorda por um a três meses até atingir cinco a dez gramas.

A gaiola possui uma cobertura e um cano de ali- mentação (RADHAKRISHNAN, 2012). Este tipo de gaiola é flexível e pode ser removida de uma área para outra quando ocorre tempestade ou tempo ruim (NGUYEN, 2009).

Figura 2: Dimensão da gaiola submersa (adaptado de Hoang, 2011 citado por Nguyen, 2012).

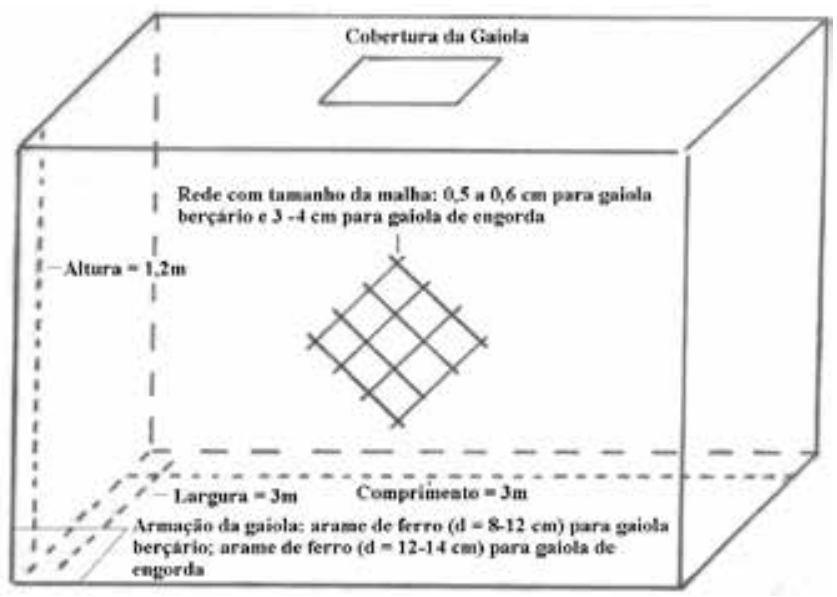

\subsubsection{Gaiolas flutuantes}

As gaiolas flutuantes (Figura 3) atualmente são o sistema de produção mais comum para engorda de lagosta no Vietnã (LE ANH; JONES, 2015). Estas gaiolas são mais vantajosas, podendo ser removidas para áreas com melhor qualidade da água.

Gaiolas flutuantes são construídas com armações, boias (PILLAI, 2013), rede de nylon e localizadas a uma profundidade de dez a 20 metros (RADHAKRISHNAN, 2012). A parte telada da gaiola flutuante é normalmente mantida com armação com boias (NGUYEN, 2009). O saco da gaiola flutuante é mantido normalmente pela armação com boias (TUAN; MAO, 2004).

Nguyen (2012) relatou que o número de pedaço ou unidades de madeira depende da escala da balsa, varia normalmente de seis a oito peças ou unidades por quadrado da gaiola e conectado com cada outro com parafuso feito de aço inoxidável. De acordo com o mesmo autor, a dimensão comum (largura $\mathrm{x}$ comprimento $\mathrm{x}$ profundidade) da gaiola é de 4 × 4 × 7 metros; há seis a oito barris ou tambores de plásticos ou latas por gaiola quadrada ou retangular usadas como boias flutuantes; ancoras são penduradas nos quatro cantos da gaiola para mantê-las segura; os filamentos de cordas com dois a quatro centímetros de diâmetro são conectadas a gaiola para gaiola junto na mesma balsa e a distância entre dois cordões é de um metro pelo menos para eliminar o impacto 
de ondas fortes, especialmente na estação de tempestades.

Estas gaiolas podem ter uma durabilidade de seis a dez anos (NGUYEN, 2009), embora com alto custo no uso de materiais duráveis como as boias flutuantes, cordas, estrutura ou armação de madeira e chapas de fibra/ lona para cobrir a gaiola que protege a lagosta do calor da luz solar (NGUYEN, 2012).

Figura 3: Dimensão da gaiola flutuante (adaptado de HOANG, 2011 apud NGUYEN, 2012).

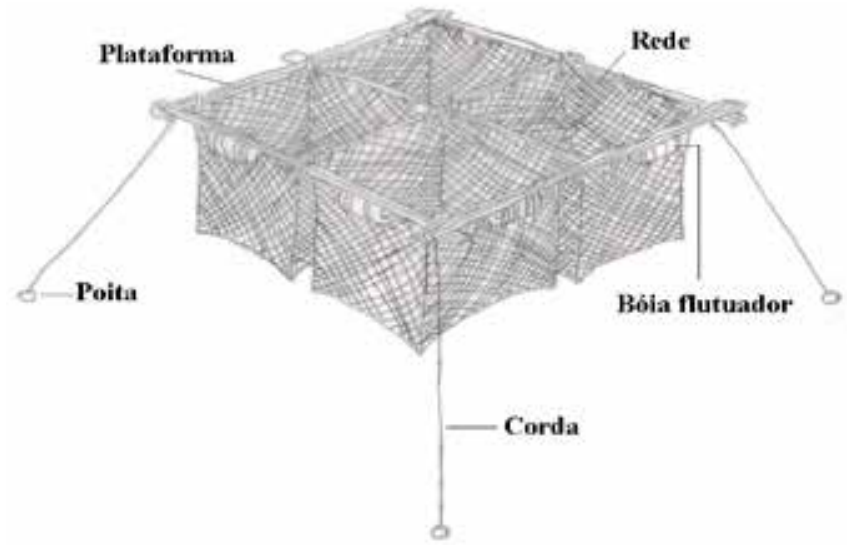

As gaiolas são mesmo quadradas ou retangulares com os lados de 2,8 - 4,0 m com 4,0 x 4,0 m sendo as dimensões mais comuns e a estrutura de suporte das gaiolas é feita de tábuas de madeira com comprimento de 3,5 - 5,0 m, largura de oito a 15 centímetros, espessura de seis a dez centímetros; com os flutuadores de apoio da estrutura da armação são tambores de plástico reusados de aproximadamente 200 L ou pequenas vasilhas de plástico com capacidade para $20 \mathrm{~L}$ (LE ANH; JONES, 2015).

\subsubsection{Gaiolas fixas de madeira}

A armação é feita de madeira resistente ao sal (PILLAI, 2013). Inicialmente os sistemas de produção compreendem gaiolas fixadas (Figura 4) com moldura exterior feito de madeira resistente ao sal, com 10-15 cm de diâmetro e quatro a cinco metros de comprimento, o qual foi encaixado a cada dois metros para criar um formato retangular ou quadrado (LE ANH; JONES, 2015). Tuan e Mao (2004) relataram que a área do fundo do cultivo é normalmente 20 a $40 \mathrm{~m}^{2}$, mas pode chegar ao tamanho de 20 a $400 \mathrm{~m}^{2}$. O tamanho da gaiola varia e a gaiola pode estar sob (acima do fundo) ou sobre o fundo (no fundo). A fixação da gaiola no fundo é de aproximadamente 0,5 metros acima do fundo (RADHAKRISHNAN, 2012).
Figura 4: Dimensão da gaiola fixa (adaptado de HOANG, 2011 apud NGUYEN, 2012).

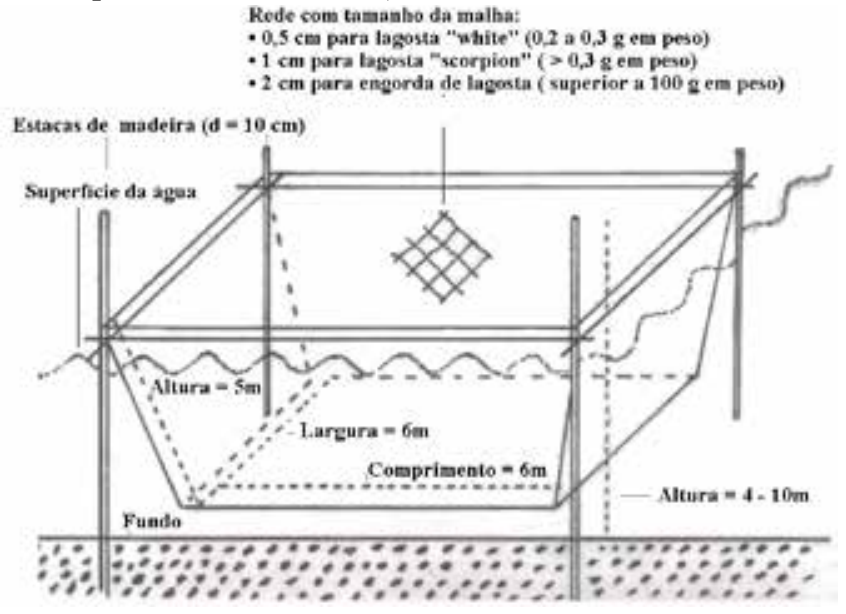

\section{Métodos de estocagem}

A engorda de lagostas no Vietnã é realizada com juvenis que podem ser capturados com redes de cerco, puçás, armadilhas e por mergulhadores na natureza. As lagostas juvenis com comprimento de $1-15 \mathrm{~cm}$ são capturadas, mas o tamanho preferido para a engorda é de quatro a seis centímetros, embora o tamanho médio de captura varia ao longo do ano (HUNG; TUAN, 2009).

A maior parte dos pueruli são transportados em pequenas caixas de isopor de motocicleta a distâncias de várias centenas de quilômetros (FAO, 2011). Nguyen (2012) relatou que a temperatura é mantida a $21-22^{\circ} \mathrm{C}$ e $23-25^{\circ} \mathrm{C}$ se a duração do transporte for de aproximadamente cinco a 15 horas ou três a cinco horas, respectivamente. As lagostas recentemente capturadas são muito sensíveis ao impacto de um novo ambiente.

Normalmente, após a captura, a lagosta é cultivada em gaiolas berçário até este obter o tamanho de cinco a dez gramas por juvenil por 30 a 40 dias (NGUYEN, 2009).

Cada gaiola é colocada sobre o fundo a dois a cinco metros de profundidade e um tubo de alimentação da superfície da gaiola provê meios de alimentar as lagostas recentes (FAO, 2011). As atividades de berçário das lagostas podem ser feitas indoor (SUPRIYONO; PRIHARDIANTO; NIRMALA, 2017). Assim os indivíduos são transferidos para gaiolas de engorda ou vendidas a outros fazendeiros.

De acordo com Radhakrishnan (2012) sementes de lagostas de aproximadamente $25-30 \mathrm{~mm}$ de comprimento total (TL) são estocadas ( 100 a 200 por gaiola) e crescem ao tamanho de aproximadamente $50 \mathrm{~g}$ (dez a $12 \mathrm{~cm}$ comprimento total). A fase de berçário tipicamente envolve a estocagem de pueruli a 50 a $100 / \mathrm{m}^{2}$ em gaiolas submersas, consistindo de rede em volta da armação de aço (FAO, 2011).

Jones et al. (2001) demonstraram que uma taxa satisfatória de crescimento de $P$. ornatus com peso inicial de estocagem de três gramas em uma alta densidade como cinco kg. $\mathrm{m}^{-2}$ poderia permitir o peso final da lagosta de um quilo na despesca em 18 meses de cultivo. Isto coincide com a experiência dos criadores do Vietnã que geralmente despescam lagostas maiores que um quilo após 18 a 20 meses de engorda na densidade de até 80 lagostas por gaiola $(4 \times 4 \mathrm{~m})(\mathrm{JO}-$ NES, 2010). P. ornatus é uma lagosta particularmente social 
(DENNIS; SKEWES; PITCHER, 1997), a produção em alta densidade não é problemática, porém outras espécies de lagostas espinhosas são conhecidas como sendo territorialistas e agressivas, tal como a $P$. versicolor os quais pode não ser ideal ao cultivo (HART, 2009).

\section{Fatores ambientais}

No Vietnã, nos locais de produção de lagostas as águas têm se caracterizada com correntes de dois a quatro $\mathrm{cm} / \mathrm{s}$, profundidade da água de nove a $20 \mathrm{~m}$, salinidade varia de 30 a $34 \%$ (TOWERS, 2014). A mudança súbita na salinidade de cinco a $15 \%$ cria uma diminuição na atividade alimentar de 30 a $90 \%$ e, se a salinidade diminui de 20 a $25 \%$ em três a cinco dias, as lagostas juvenis morrem lentamente e as maturas não podem comer (NGUYEN, 2012). A temperatura da água varia de 22 a $32{ }^{\circ} \mathrm{C}$ (TOWERS, 2014). Um aumento repentino na temperatura de três a cinco graus Celsius causará a morte da maioria dos juvenis de diferentes espécies, enquanto uma diminuição de cinco graus Celsius levará ao crescimento lento e a paralisação completa da fase de muda da lagosta (NGUYEN, 2012). O total de nitrogênio na água do mar chegou a exceder o nível padrão para aquicultura de $0,4 \mathrm{mg} / \mathrm{L}$ (RADHAKRISHNAN, 2012).

\section{Combinação de alimento no cultivo de lagosta}

No Vietnã, as lagostas são alimentadas exclusivamente com peixe fresco inteiro ou cortado em pedaço e mariscos. Peixes podem compreender aproximadamente 70 $\%$ da dieta e o peixe preferido é o lizardfish (peixe lagarto) (RADHAKRISHNAN, 2012) e os outros $30 \%$ de mariscos (TUAN; MAO, 2004). O peixe preferido lizardfish (peixe lagarto) compreende $38 \%$ de peixe na alimentação (TUAN; MAO, 2004; RADHAKRISHNAN, 2012). Portanto, as espécies ou grupos comumente utilizados para alimentar as lagostas são peixe lagarto (Saurida spp.); red big eye (Priacanthus spp.); pony fish (Leiognathus spp.); pomfret (peixe da família Bramidae); caracois, ostras, certos moluscos bivalves como o berbigão e a amêijoa; siri, caranguejos e camarões (LAI; LE, 2009). Os moluscos compreendem lula, "choco" cuttlefish e alguns mariscos (LE ANH; JONES, 2015).

Pillai (2013) relatou que as lagostas são alimentadas três a quatro vezes ao dia. Tuan e Mao (2004) relataram que as lagostas de maior tamanho (>400 g/indivíduo) são alimentadas uma a duas vezes ao dia. Nguyen (2009) relatou que à noite os criadores usualmente fornecem mais alimentos para as lagostas devido às lagostas serem extremamente ativas durante à noite.

Mais de $20 \mathrm{~kg}$ e em alguns casos mais de $50 \mathrm{~kg}$ de uma mistura de rejeito de pesca podem ser necessários para produzir um quilo de lagosta no Vietnã (JONES, 2010). A taxa de conversão alimentar para lagosta utilizando esta dieta lizardfish (peixe lagarto) pode ser de aproximadamente 1730 (base do peso fresco) (TUAN; MAO, 2004). Portanto, a taxa de conversão alimentar (FCR) do rejeito de pesca pode variar de 17 a 30 sob uma base de peixe fresco. O rejeito de pesca é cortado em pedaços e as conchas dos mariscos removidas (TUAN; MAO, 2004).

Em relação a outras formas de cultivo, não há custos como em viveiros terrestres e os custos financeiros podem ser mais modestos para estruturas em gaiolas (PETERSEN; PHUONG, 2010). O custo da alimentação usando como fonte de alimento rejeito de pesca tradicional pode ser bastante alto devido à taxa de conversão alimentar pobre, resultado da composição inapropriada e qualidade pobre, e o consumo de alimento peletizado manufaturado poderá diminuir o custo da alimentação (TUAN; HUNG, 2009).

\section{Período de cultivo}

O período de cultivo de cada espécie varia (Tabela 1). A P. ornatus é cultivada durante um período de aproximadamente 20 - 24 meses para chegar ao tamanho comercial de $800-1000 \mathrm{~g} /$ indivíduo, para outras espécies requer 12 - 15 meses para chegar a 200 - 300 g/ indivíduo (TOWERS, 2014).

Tabela 1: Características de diferentes espécies lagostas no Vietnã.

\begin{tabular}{l|l}
\hline Espécies & Taxa de engorda \\
\hline Panulirus ornatus (spiny lobster) & Rápida $(>1 \mathrm{~kg} / 18$ meses de cultivo $)$ \\
\hline Panulirus homarus (green lobster) & Médio $(0,35-0,40 \mathrm{~kg} / 18$ meses de cultivo) \\
\hline Panulirus polyphagus (bamboo lobster), Panulirus longipes (red lobster) & $(0,25-0,35 \mathrm{~kg} / 18 \mathrm{meses}$ de cultivo) \\
\hline Fonte: Nguyen (2009). &
\end{tabular}

As duas espécies mais cultivadas no Vietnã até o momento são $P$. ornatus ou spiny lobster e $P$. hormarus ou green lobster que corresponde a mais de $90 \%$ (NGUYEN, 2009).

\section{Considerações finais}

As principais limitações para a engorda de lagostas podem ser enfermidade, mortalidade de puerulus capturado na natureza, problemas na alimentação com rejeito de pesca, disponibilidade de locais com gaiolas no mar.

No entanto, devido à lagosta maturar e reproduzir em cativeiro e poder ser engordadas juntas, fazem deste um crustáceo com potencialidade para a engorda comercial provavelmente de médio a longo prazo. Porém, poucos trabalhos foram realizados com o objetivo da engorda em larga escala na produção comercial no Brasil.

O mais importante atualmente pode ser o suprimento suficiente de juvenis recentes para o cultivo comercial, desenvolvimento de dietas artificiais eficientes e desenvolvimento de métodos de cultivo em larga escala. Portanto, os maiores problemas enfrentados não somente no Brasil para o sucesso dos projetos de engorda de lagostas são os longos períodos para o retorno do investimento e a obtenção de um retorno financeiro. Por outro lado uma boa base financeira parece ter sido recebida pelos japoneses, graças ao qual 
tem conseguido realizar enormes progressos no cultivo de lagostas.

\section{Agradecimentos}

Agradeço ao Professor Jiro Kittaka "In Memorian" da Universidade de Ciência de Tokyo pelos conhecimentos adquiridos sobre o cultivo de lagostas.

\section{Referências}

$\mathrm{DAO}, \mathrm{H}$. T. Recruitment and genetic population genetics of spiny lobsters, Panulirus ornatus and $P$. homarus in the south-east Asian archipelago. Queensland, James Cook University. 2016. $155 \mathrm{f}$. Thesis (Doctor of Philosophy in the Centre for Sustainable Tropical Fisheries and Aquaculture) College of Science and Engineering James Cook University.

DENNIS, D. M.; SKEWES, T. D.; PITCHER, C. R. Habitat use and growth of juvenile ornate rock lobsters, Panulirus ornatus (Fabricius, 1798), in Torres Strait, Australia. Marine and Freshwater Research, Collingwood, v. 48, n. 8, p. 663670, 1997.

DENNIS, D. M.; PITCHER, C. R.; SKEWES, T. D. Distribution and transport pathways of Panulirus ornatus (Fabricius, 1776) and Panulirus spp. larvae in the Coral Sea, Australia. Marine and Freshwater Research, Collingwood, v. 52, p. $1175-118,2001$.

ECHAURI, J. J. G.; JEFFS, A. Energy expenditure of migrating spiny lobster post larvae. 11th International Conference \& Wokshop on Lobster Biology \& Management. Abstracts, Portland, Maine July 4-9, 2017. p. 76.

FAO. Cultured aquatic species information programme. Panulirus homarus. Cultured aquatic species information programme. Text by Clive, J. In FAO Fisheries and Aquaculture Department. Rome. Update 16 september 2011. Disponível em: <http://www.fao.org/fishery/culturedspecies/ Panulirus_homarus/en>. Acesso em: 05 jan. 2017.

FAO. Programa Estatístico FishStatJ: Global Fishery and Aquaculture Statistics. Food and Agriculture Organization of the United Nations (Org.). Disponível em: Rome: Database global aquaculture production 1950-2014. Disponível em: <(http://www.fao.org/fishery/statistics/ global-aquacultureproduction/en),2016b $>$. Acesso em: 1 jun. 2016.

FITZGIBBON, Q. P.; JEFFS, A. G.; BATTAGLENE, S. C. The Achilles heel for spiny lobsters: the energetics of the non-feeding post-larval stage. Fish and Fisheries, v. 15, n. 2, p. 312-326, 2014.

HART, G. Assessing the South-East Asian tropical lobster supply and major market demands. ACIAR Final Report (FR-2009-06). Australian Centre for International Agricultural Research, Canberra, 2009.

HOANG, Dimension of floating cage. 2011. Disponível em
$<$ https://munin.uit.no/bitstream/handle/10037/4756/thesis. pdf? sequence=2>. Acesso em: 08 out. 2017.

HOLTHUIS, L. B. FAO species catalogue. v. 13. Rome, 1991. Marine lobsters of the world. An annotated andillustrated catalogue of species of interest to fisheries known to date. FAO Fisheries Synopsis. n. 125, FAO, v. 13. 1991. 292 p.

HUNG, L. V.; TUAN, L. A. Lobster seacage culture in Vietnã. In: Williams, K. C., Proceedings of an International Symposium on Spiny Lobster Aquaculture in the Asia-Pacific Region, Australian Centre for International Agricultural Research, Canberra. Spiny Lobster Aquaculture in the AsiaPacific Region, Proceedings... Canberra: ACIAR, 2009. p. $10-17$.

JONES, C. M. et al. Effect of density on growth and survival of ornate rock lobster, Panulirus ornatus (Fabricius, 1798), in a flowthrough raceway system. Marine and Freshwater Research, Australia, v. 52, n. 8, p. 1.425-1.429, 2001.

JONES, C. M. Report on overseas travel to Indonesia and Vietnã, July/August, 2009. Bruce, 2009. ACIAR Project SMAR/2008/021: Spiny lobster aquaculture development in indonesia, Vietman and Australia. Queensland Primary Industres anf Fisheries (QPIF) and the Australian Centre for International Agricultural Research (ACIAR), 2009.

JONES, C. M. Tropical spiny lobster aquaculture development in Vietnã, Indonesia and Australia. Journal Marine Biology Association, India, v. 2, n. 2, p. 304-315, jul./dec. 2010.

JONES, C. M. et al. Exploitation of puerulus settlement for the development of tropical spiny lobster aquaculture in the Indo-West Pacific. Journal Marine Biology Association, India, v. 52, n. 2, p. 292-303, 2010.

JONES, C. M. Summary of disease status affecting tropical spiny lobster aquaculture in Vietnã and Indonesia. Spiny lobster aquaculture development in Indonesia, Vietnã, and Australia. In: INTERNATIONAL LOBSTER AQUACULTURE SYMPOSIUM HELD IN LOMBOK, Indonesia. Proceedings... Canberra: ACIAR, 2015, p. 111113.

KENWAY, M. et al. Potential of sea cage culture of Panulirus ornatus in Australia. In: Williams, K. C. INTERNATIONAL SYMPOSIUM ON SPINY LOBSTER AQUACULTURE IN THE ASIA-PACIFIC REGION, AUSTRALIAN CENTRE FOR INTERNATIONAL AGRICULTURAL RESEARCH. Proceedings... Canberra: ACIAR, 2009, p. 18-25.

KITTAKA, J. Larval rearing. In: Phillips, B. F., Cobb, J. S., Kittaka, J. ed. Spiny lobster management. Oxford: Fishing News Books. p. 402-423, 1994.

LAI, V. H.; LE, A. T. Lobster Sea Cage Culture In Vietnã, Proceeding of Tropical Spiny Lobster Aquaculture Symposium, Nha Trang - Vietnã, p. 10 - 17. Spiny lobster aquaculture in the Asia - Pacific region. In: INTERNATIONAL SYMPOSIUM HELD AT NHA 
TRANG, Vietnã, 9-10 December 2008. ACIAR, n. 132. Australian Centre for International Agricultural Research. Proceedings... Canberra: ACIAR. 2009, 162 p.

LE ANH, T.; JONES, C. Status report of Vietnã lobster grow-out. 2015. In Spiny lobster aquaculture development in Indonesia, (Editor: Clive M. Jones) Vietnã and Australia, In: INTERNATIONAL LOBSTER AQUACULTURE SYMPOSIUM HELD IN LOMBOK, Indonesia, 22-25 April 2014. Proceedings ... Canberra: ACIAR, 2014. p. 82 - 86.

LUCAS, J. S.; SOUTHGATE, P. C. Aquaculture: Farming Aquatic Animals and Plants.: Blackwell Publishing, Oxford. Pahlevi, R. S. 2009. In: WILliAMS, K. C. Potential for co-management of lobster seacage culture: a case study in Lombok, Indonesia. Proceedings of an International Symposium on Spiny Lobster Aquaculture in the Asia-Pacific Region, Australian Centre for International Agricultural Research. Proceedings ... Canberra: ACIAR, 2003. p. 26.

NGUYEN, THI Y LY. Economic analysis of the environmental impact on marine cage lobster aquaculture in Vietnã. 2009, 85 f. Thesis (Doctor in Fisheries and Aquaculture Management and Economics) - The Norwegian College of Fishery Science University of Tromso, Norway \& Nha Trang University, Vietnã, 2009.

NGUYEN, T. K. T. Opportunities and challenges in lobster marine aquaculture in Vietnã: the case of Nha Trang bay. 66 f. 2012. Master Thesis in Fisheries and Aquaculture Management and Economics. The Norwegian College of Fishery Science University of Tromso, Norway \& Nha Trang University, Vietnã May 2012 Disponível em $<$ http://munin. uit.no/bitstream/handle $/ 10037 / 4756 /$ thesis.pdf? sequence $=2$ $>$ Acesso em: 21 out. 2015 .

PETERSEN, E. H.; PHUONG, T. H. Tropical spiny lobster (Panulirus ornatus) farming in Vietnã - bioeconomics and perceived constraints to development. Aquatic Research, England, v. 41, n. 10, p. 634-642, 2010.

PHILLIPS, B. F. et al. Panulirus species. In: PHILLIPS, B. F. Lobsters: biology, management, aquaculture, and fisheries. 2nd edition. Wiley-Blackwell; Oxford: 2013. p. $289-325$

PILLAI, S. L. Hatchery and farming of spiny lobster an overview. [Teaching Resource]. Central Marine Fisheries Research Institute, 2013, 7 p. Disponível em: <http:// eprints.cmfri.org.in/9733/1/S_Lakshmi_Pillai.pdf $>$. Acesso em: 20 out. 2015

PRIYAMBODO, B.; JONES, C. M.; SAMMUT, J. The status of spiny lobster aquaculture in Indonesia. In: ASIAN-PACIFIC AQUACULTURE 2017. Kuala Lumpur Abstract... Kuala Lumpur, APA, - Meeting of World Aquaculture Society, 2017. Disponível em <https:/www. was.org/meetings/ShowAbstract.aspx? $\mathrm{Id}=47778>$. Acesso em: 26 set. 2017

RADHAKRISHNAN, E. V. Review of Prospects for
Lobster Farming in Handbook on Open Sea Cage Culture. In: PHILIPOSE, K. K.; LOKA, J.; SHARMA, S. R. K.; DAMODARAN, D. Central Marine Fisheries Research Institute Karwar Research Centre, 2012, p. 96-106. Disponível em: <http://eprints.cmfri.org.in/9180/1/ Handbook_on_Opensea_Cage_Culture.pdf $>$. Acesso em: 20 out. 2015

PRIYAMBODO, B.; SARIFIN, B. Lobster aquaculture industry in eastern Indonesia: present status and prospects. Lobster Sea Cage Culture In Vietnã, Proceeding of Tropical Spiny Lobster Aquaculture Symposium, Nha Trang - Vietnã, p. 36-45, 2009. Editor: Kevin C. Williams 2009. Spiny lobster aquaculture in the Asia-Pacific region. Proceedings of an international symposium held at Nha Trang, Vietnã, 9-10 December 2008. ACIAR Proceedings No. 132. Proceedings... Canberra: Australian Centre for International Agricultural Research, 2009, 162 p.

SMITH, G. G. et al. The why, where, and how of spiny lobster aquaculture (Panulirus ornatus). 11th International Conference \& Wokshop on Lobster Biology \& Management. Abstracts, Portland: ICLW. July 4-9, 2017. p. 52.

SMITH, G. A dream soon to become a reality? International Aquafeed, Cheltenham, UK, v. 20, n. 7 p. 32 - 34, 2017.

SUPRIYONO, E.; PRIHARDIANTO, R. W.; NIRMALA, K. The stress and growth responses of spiny lobster Panulirus homarus reared in recirculation system equipped by PVC shelter. AACL, Bioflux, Romania, v. 10, n. 2, p. 147-155, 2017.

TOWERS, L. Spiny lobster farming in Vietnã and the role of probiotics during production. The Fish Site, USA. 2014. Disponível em <http://www.thefishsite.com/articles/1798/ spiny-lobster-farming-in-viet-nam-and-the-role-ofprobiotics-during-production/?>. Acesso em: 25 out. 2015.

TUAN, L. A.; HUNG, L. V. Comparison of biological, economic and environmental efficiency of sea cage culture of Panulirus ornatus lobsters using different practical diets. In: K. C. Williams (Ed.), Proceedings of an International Symposium on Spiny Lobster Aquaculture in the Asia-Pacific Region, Australian Centre for International Agricultural Research. Proceedings... Canberra: ACIAR, 2009, p. 110115 .

TUAN, L. A.; MAO, N. D. Present Status of Lobster Cage Culture in Vietnã In Williams, Kevin C. (Ed.) 2004. Spiny lobster ecology and exploitation in the South China Sea region. Proceedings of a workshop held at the Institute of Oceanography, Nha Trang, Vietnã, July 2004. Proceedings... Canberra: ACIAR, 2004. n. 120, p. 21 a 25, 2004. Disponível em: <http://aciar.gov.au/files/node/590/pr120 pdf 17638. pdf $>$. Acesso em: 22 out. 2015.

THUY, N. T. B.; NGOC, N. B. Current status and exploitation of wild spiny lobsters in Vietnãese waters. In: K. C. Williams (Ed.), Proceedings of a Workshop on Spiny Lobster Ecology and Exploitation in the South China Sea Region. ACIAR 
Proceedings No. 120, Australian Centre for International Agricultural Research, Proceedings... Canberra: ACIAR, 2004, n. 4, p. 13-16.

WILLIAMS, K. C. Nutritional requirements and feeds development for post-larval spiny lobster: A review. Aquaculture, v. 263, n. 2, p. 1-14, 2007.

Recebido em: 29.11.2017. Aceito em: 28.12.2018. 